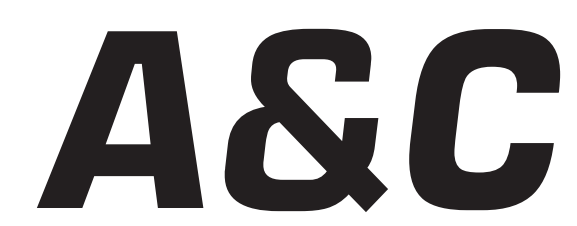

Revista de Direito Administrativo \& Constitucional

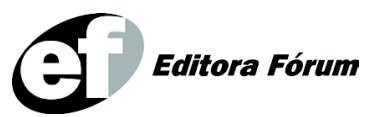

ISSN 1516-3210 


\section{A\&C REVISTA DE DIREITO ADMINISTRATIVO E CONSTITUCIONAL}

IPDA

Instituto Paranaense

de Direito Administrativo

Direção Geral

Romeu Felipe Bacellar Filho

Direção Editorial

Paulo Roberto Ferreira Motta

Direção Executiva

Emerson Gabardo

Conselho de Redação

Edgar Chiuratto Guimarães

Adriana da Costa Ricardo Schier

Célio Heitor Guimarães

\section{Conselho Editorial}

Adilson Abreu Dallari

Alice Gonzáles Borges

Carlos Ari Sundfeld

Carlos Ayres Britto

Carlos Delpiazzo

Cármen Lúcia Antunes Rocha

Celso Antônio Bandeira de Mello

Clèmerson Merlin Clève

Clóvis Beznos

Enrique Silva Cimma

Eros Roberto Grau

Fabrício Motta

Guilhermo Andrés Muñoz (in memoriam)

Jaime Rodríguez-Arana Muñoz

Jorge Luís Salomoni

José Carlos Abraão
José Eduardo Martins Cardoso
José Luís Said
José Mario Serrate Paz
Juan Pablo Cajarville Peruffo
Juarez Freitas
Julio Rodolfo Comadira
Luís Enrique Chase Plate
Lúcia Valle Figueiredo
Manoel de Oliveira Franco Sobrinho
(in memoriam)
Marçal Justen Filho
Marcelo Figueiredo
Márcio Cammarosano
Maria Cristina Cesar de Oliveira

Nelson Figueiredo

Odilon Borges Junior

Pascual Caiella

Paulo Eduardo Garrido Modesto

Paulo Henrique Blasi

Paulo Neves de Carvalho (in memoriam)

Paulo Ricardo Schier

Pedro Paulo de Almeida Dutra

Regina Maria Macedo Nery Ferrari

Rogério Gesta Leal

Rolando Pantoja Bauzá

Sérgio Ferraz

Valmir Pontes Filho

Yara Stropa

Weida Zancaner

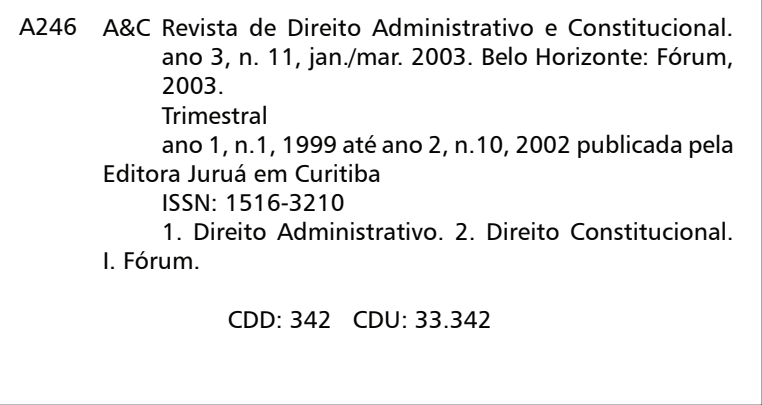

(C) Editora Fórum Ltda. 2007

Todos os direitos reservados. É proibida a reprodução total ou parcial, de qualquer forma ou por qualquer meio eletrônico ou mecânico, inclusive através de processos xerográficos, de fotocópias ou de gravação, sem permissão por escrito do possuidor dos direitos de cópias (Lei nº 9.610, de 19.02.1998).

Editora Fórum Ltda

Av. Afonso Pena, $2770-15 \% 16^{\circ}$ andar - Funcionários

CEP 30130-007 - Belo Horizonte/MG - Brasil

Tel.: 08007043737

Internet: www.editoraforum.com.br

e-mail: editoraforum@editoraforum.com.br
Editor responsável: Luís Cláudio Rodrigues Ferreira Projeto gráfico e diagramação: Luis Alberto Pimenta Revisora: Olga M. A. Sousa

Pesquisa jurídica: Fátima Ribeiro - OAB/MG 74868

Bibliotecária: Leila Aparecida Anastácio

CRB 2809/MG 6ª região

Os conceitos e opiniões expressas nos trabalhos assinados são de responsabilidade exclusiva de seus autores.

Impressa no Brasil / Printed in Brazil

Distribuída em todo Território Nacional 


\title{
Democracia, direitos humanos e proteção ao meio ambiente no contexto da integração regional
}

\author{
Eduardo Biacchi Gomes* \\ Advogado. Doutor em Direito do Estado pela Universidade Federal do Paraná. Professor de Direito \\ da Integração, Curso de Direito e da Pós-Graduação, Especialização e Mestrado da UniBrasil. \\ Membro do Nupeconst e do Nupesul.
}

\begin{abstract}
Resumo: Proteção ao meio ambiente e desenvolvimento sustentável, cada vez mais, ganham destaque no contexto da integração regional. O presente artigo aborda dois famosos casos do Tribunal Permanente de Revisão, que envolvem temas relevantes no cenário internacional: a democracia e a proteção aos direitos humanos.
\end{abstract}

Palavras-chave: Mercosul. Protocolo de Olivos. Direitos Humanos. Proteção ao Meio Ambiente. Barreiras não-tarifárias.

Sumário: 1 Introdução - 2 Laudos arbitrais do Mercosul - 2.1 Laudo Arbitral $n^{\circ} 1 / 2005$ do Tribunal Permanente de Revisão - 2.1.2 Laudo Arbitral no 2/2006 - 3 Considerações finais

\section{Introdução}

O Mercosul, enquanto processo de integração regional, tem trazido aos estudiosos do tema casos interessantes sobre a questão em seu sistema de solução de controvérsias, alterado, recentemente, através do Protocolo de Olivos no ano de 2002.

Para o sucesso de qualquer processo de integração, torna-se necessária a existência de um eficaz sistema de solução de controvérsias, a fim de conferir maior segurança jurídica ao bloco econômico.

À medida que as negociações comerciais vão se intensificando, as controvérsias, julgadas pelo Tribunal $A d$ Hoc passam a debater temas que transcendem questões eminentemente comerciais, passando a abordar questões de relevante interesse, não somente aos Estados envolvidos, mas quanto aos demais sócios do Mercosul.

Referidas controvérsias, além de envolver temas que transcendam os interesses dos Estados envolvidos, igualmente diz respeito aos interesses dos cidadãos do Mercosul, como, por exemplo, os temas relativos à proteção ao meio ambiente e questões voltadas à proteção dos direitos humanos

*E-mail: < Gomes_eduardo@uol.com.br>. 
e a democracia, valores essenciais em qualquer Estado e que, cada vez mais, estão presentes nos processos de integração, o que bem demonstra a relevância das referidas questões no contexto do Mercosul que, efetivamente, inaugura uma nova era, com a inclusão de temas relevantes aos cidadãos do bloco econômico e servem para reduzir o chamado déficit democrático nas instituições do bloco.

Referido déficit democrático é caracterizado pela falta de legitimidade na tomada das decisões, adotadas pelas Instituições do Mercosul que, na maioria dos casos, não leva em consideração os reais interesses dos cidadãos, o que é explicado pela ausência de instituições, de caráter permanente no bloco, com a finalidade de representar os interesses dos particulares, gerando um vácuo de legitimidade, entre as políticas adotadas pelos órgãos do bloco e os interesses dos cidadãos do Mercosul.

Assim, os outrora laudos arbitrais do antigo Protocolo de Brasília, que antes abordavam questões eminentemente econômicas e comerciais, tais como a prática de subsídios, imposição de barreiras tarifárias e nas tarifárias, passam a ser examinados sob uma nova ótica, a partir dos interesses dos particulares, como a proteção ao meio ambiente, a observância dos direitos humanos e da democracia.

O presente artigo tem por finalidade abordar o Laudo Arbitral $\mathrm{n}^{\circ}$ 1 do Tribunal Permanente de Revisão, entre o Uruguai e a Argentina e que teve por objeto examinar a importação dos pneus remoldados e que trabalhou com o conceito de barreiras não tarifárias, pautadas na proteção ao meio ambiente.

O Laudo Arbitral no 2, oriundo do Tribunal $A d H o c$, que, igualmente, entre o Uruguai e a Argentina, teve por finalidade examinar o reclamo uruguaio, em relação aos bloqueios, realizados pelos argentinos, em cidade fronteiriça uruguaia, onde, supostamente, estaria havendo limitações ao livre trânsito de pessoas e de bens, objetivos estabelecidos no Tratado de Assunção, 1991.

Importante destacar que, no referido Laudo Arbitral, ambas as partes alegaram violações aos direitos humanos. Do lado uruguaio, as alegações foram no sentido de que os referidos protestos violavam o direito de livre trânsito dos seus cidadãos e, do lado argentino, os protestos seriam legítimos, tendo em vista o direito constitucional assegurado da livre expressão e de manifestação de pensamento.

Outro argumento utilizado, pela Argentina, foi que os protestos 
foram legítimos e pacíficos, não justificando a intervenção do governo federal, pois, quando muito, a atuação deveria se dar no âmbito provincial.

\section{Laudos arbitrais do Mercosul}

Como forma de melhor demonstrar ao leitor os pontos ora abordados, torna-se importante examinarmos os Laudos de $\mathrm{n}^{\circ} 1$ e $\mathrm{n}^{\mathrm{o}} 2$, emanados pela Sistemática do Protocolo de Olivos, 2002.

\subsection{Laudo Arbitral n 1/2005 do Tribunal Permanente de Revisão}

Referido Laudo Arbitral teve por finalidade revisar, em grau de recurso, o laudo proferido pelo Tribunal $A d H o c$ do Mercosul, datado de 25 de outubro de 2005, e que teve por objeto dirimir a controvérsia sobre "Proibição de Importação de Pneus Remoldados, oriundos do Uruguai, com destino para a Argentina."

Figuraram como partes a República Oriental do Uruguai, como Reclamante, e a República da Argentina, como Reclamada. O Laudo Arbitral foi proferido na cidade de Assunção, sede do Tribunal Permanente de Revisão, em data de 20 de dezembro do ano de 2005.

O Tribunal foi composto pelos seguintes árbitros: Nicolas Becerra (Argentina), Ricardo Oliveira (Uruguai) e Wilfrido Fernández (Paraguai).

Referido Recurso de Revisão foi apresentado, junto ao Tribunal Permanente de Revisão, em data de 09 de novembro do ano de 2005. Da controvérsia foram notificados os Terceiros Estados, não envolvidos no litígio: a República Federativa do Brasil e a República do Paraguai.

O Tribunal foi constituído para revisar, exclusivamente, as questões de direito, no primeiro caso para o qual foi designado.

Após fazer uma breve digressão sobre a importância dos Tribunais Recursais, que tiveram origem na França, através dos Recursos de Cassação, que surgiram no século XX, na Europa, e logo foram adotadas na América Latina, como forma de unificar a jurisprudência.

Nesse sentido, a Argentina defendeu a tese de que a controvérsia deveria se resumir na questão de se a aplicação e a interpretação dos princípios e conceitos, relativos ao livre comércio, comportariam exceções, entre elas as dispostas no artigo 50 do Tratado de Montevidéu, 1980 (TM/80). ${ }^{1}$

No caso em exame, a controvérsia, em nosso entender, diz respeito à aplicação de barreiras não-tarifárias, por parte da Argentina, no que

Os produtos importados ou exportados por um País Membro gozarão de liberdade de trânsito dentro dos demais Países Membros e estarão sujeitos exclusivamente ao pagamento das taxas aplicáveis à prestação de serviços. 
diz respeito à justificativa em relação à proibição da importação de pneus remoldados, ou seja, referidos materiais, que são sólidos, são de difícil decomposição e causam prejuízos ao meio ambiente.

Assim dispõem as alíneas $b$ e $d$, mencionadas pelo Tribunal Permanente de Revisão, do artigo 49, Tratado de Montevidéu:

Nenhuma disposição do presente Tratado será interpretada como impedimento à adoção e ao cumprimento de medidas destinadas à:

a)

b) Aplicação de leis e regulamentos de segurança;

c)

d) Proteção da vida e saúde das pessoas, dos animais e dos vegetais.

e)

f)

Segundo o Tribunal, o objeto da Controvérsia diz respeito ao disposto na Lei argentina de $\mathrm{n}^{\circ} 25.626$, datada de 08 de agosto do ano de 2002, que proibiu a importação de pneus remoldados oriundos do Uruguai; o entendimento de que o objeto englobaria qualquer outro texto legal ou administrativo, que contemplasse a mesma matéria, segundo era intenção do Uruguai, está incorreto, segundo entendeu o TPR (Tribunal Permanente de Revisão), ante a violação aos princípios da especificidade e da abstração, isto é: de que o Tribunal deverá examinar o caso em concreto, garantindo, assim, maior segurança jurídica na tomada de suas decisões.

Utilizando precedentes do Tribunal de Justiça das Comunidades Européias e do Tribunal da Comunidade Andina, entendeu o TPR que, mesmo quando o Estado infrator, no curso da demanda, altera a Lei, objeto da controvérsia, a qual, ainda, possui os mesmos efeitos questionados, referido Estado ainda poderá ser condenado a eliminar as restrições ao comércio regional.

Assim, o objeto da controvérsia resume-se a aplicação do princípio de livre circulação de mercadorias e as respectivas exceções.

Quanto à aplicação do primeiro princípio, como bem esclareceu o Tribunal, o mesmo está inserido nos Tratados Fundacionais do Mercosul, sendo, ainda, fato incontroverso no primeiro Laudo Arbitral, vez que ambas as partes reconheceram a existência no referido princípio. 
Certo é que o Princípio da Livre Circulação de Mercadorias, consoante reconheceu o TPR, contempla exceções, entre elas as previstas no artigo 50 do Tratado de Montevidéu, de 1980.

Ao examinar as hipóteses de exceção ao livre comércio, o TPR entende que para que a restrição ao livre comércio seja considerada como lícita, torna-se necessária a sua efetiva comprovação, como seria o caso de violações ao meio ambiente.

O TPR define como critério para a aplicação dos Princípios do Livre Comércio e de Proteção ao Meio Ambiente, não atribuindo uma escala valorativa, no sentido de saber qual deve prevalecer, mas, sim, procura compatibilizar a aplicação dos princípios, no sentido de se saber, qual, no caso em concreto, em virtude das normativas existentes, deverá ser aplicado.

O critério utilizado pelo TPR foi buscar a existência de um Marco Jurídico, no contexto do Mercosul, que justificasse a adoção da referida exceção, tendo em vista que o nosso bloco econômico possui um ordenamento jurídico próprio, emanado do Direito da Integração, que, consoante reconheceu o Tribunal, é distinto do Direito Comunitário e cada vez mais ganha autonomia frente ao Direito Internacional.

Como princípio básico e elementar, aplicado pelo TPR, foi o do ônus da prova, isto é, aquele que alega a aplicação de uma exceção ao comércio internacional deverá prová-la. Assim, à Argentina foi incumbido o ônus de comprovar a existência dos referidos danos ao meio ambiente, afastando, de plano, a aplicação de qualquer normativa estranha ao quadro jurídico do Mercosul.

Continuando, o TPR, concluindo pela ausência de uma normativa, no contexto do Mercosul, examina a questão sob os seguintes fundamentos: a) de averiguar se a conduta adotada pela Argentina é caracterizada como restritiva ao livre-comércio. Nesse quesito, o TPR entendeu que a conduta argentina viola o livre-comércio, à medida que ela não estaria justificada.

Concluindo se tratar de uma medida restritiva ao livre-comércio, o TPR examina o segundo aspecto da questão: b) se a mesma é discriminatória, a resposta do Tribunal é positiva, notadamente porque a medida afeta, exclusivamente, os produtos estrangeiros.

O terceiro pressuposto diz respeito de se saber se a conduta adotada pela Argentina seria justificada, isto é, se as restrições impostas teriam como finalidade proteger o meio ambiente (c). Mais uma vez, a conclusão 
do TPR foi negativa, posto que a legislação argentina, antes de proteger o meio ambiente, tinha por finalidade incentivar as indústrias nacionais.

O quarto pressuposto (d), refere-se ao critério da proporcionalidade, isto é, se a conduta argentina, visando proteger o meio ambiente, foi proporcional, a fim de atingir o objetivo pretendido. De acordo com as conclusões do TPR, as proibições adotadas pela Argentina não acarretaram na melhora do meio-ambiente, vez que não houve qualquer redução ao chamado dano ambiental. Entendeu, ainda o TPR, que o critério da proporcionalidade estava ausente, vez que os referidos danos não seriam graves nem irreversíveis.

Reformando a decisão do Tribunal $A d H o c$, que tinha invertido o ônus probatório, isto é, determinando ao Uruguai que comprovasse a inexistência de quaisquer danos ao meio ambiente, o TPR entendeu que, no âmbito da Integração, inexiste a referida inversão do ônus da prova e incumbe a parte que alega a aplicação de alguma restritiva ao livre-comércio, o ônus de comprovar a licitude da referida conduta.

Quanto ao conceito do estopell ${ }^{2}$ entendeu o TPR que, no contexto da integração regional, o mesmo, que é muito utilizado no Direito Internacional, também pode ser aplicado no Direito da Integração, entretanto como último recurso.

Finalmente, entendeu o TPR que os terceiros países (Brasil e Paraguai) deveriam ter conhecimento dos termos da referida decisão, notadamente porque o Brasil foi favorável à posição da Argentina e o Paraguai à posição do Uruguai.

Concluindo, o TPR, por maioria, reformou a decisão do Tribunal Ad Hoc de forma a determinar que a Argentina alterasse a sua legislação, para permitir a entrada dos pneus remoldados oriundos do Uruguai e que a Lei de $n^{\circ} 25.626$ da Argentina é incompatível com as normas do Mercosul e com as exceções do artigo 50 do TM/80. Dispôs, ainda, por maioria, que a presente terá validade provisória, até que o Mercosul regulamente a questão.

Os honorários dos árbitros foram divididos em partes iguais, entre os Estados-Partes, sendo que o Laudo Arbitral terá eficácia imediata.

\footnotetext{
2 Conceito de Direito Internacional, que visa preservar a boa-fé nas relações entre os parceiros comerciais, evitando que uma parte, unilateralmente e sem qualquer justificativa, altere a sua conduta, visando dar maior segurança jurídica.
}

A \& C R. de Dir. Administrativo e Constitucional, Belo Horizonte, ano 7, n. 27, p. 121-135, jan./mar. 2007 


\subsubsection{Laudo Arbitral $n^{\circ}$ 2/2006}

O segundo Laudo Arbitral, proferido pelo Tribunal Ad Hoc, do Protocolo de Olivos, foi proferido em 6 de setembro de 2006 na cidade de Montevidéu.

O tribunal foi constituído pelos seguintes árbitros: Luís Martí Mingarro (Presidente-Espanha), José Maria Gamio (Uruguai) e Enrique Carlos Barreira (Argentina) e teve por objetivo julgar o reclamo, interposto pelo Uruguai, referente à "Omissão do Estado da Argentina em relação a não adoção de medidas para prevenir ou não combater os protestos, adotados por seus cidadãos que culminaram em prejudicar a livre circulação de pessoas e de bens, decorrentes dos protestos, realizados na Argentina, em vias de acesso às Pontes internacionais denominadas Gral. San Martín e Gral. Artigas, que unem os dois países."

A controvérsia em questão diz respeito à construção de duas fábricas de celulose (papeleras), que estão sendo construídas na cidade uruguaia de Gualenguaychú, que faz fronteira com a cidade argentina de Fray Bentos.

Referidas cidades são cortadas pelo Rio Uruguai e, no ano de 1975, a Argentina e o Uruguai celebraram o Tratado sobre o Rio Uruguai, visando à proteção do referido Rio Uruguai.

Assim, desde o ano de 2003, a Argentina vem realizando protestos sobre as pontes que ligam as cidades fronteiriças, acarretando prejuízos ao Uruguai, relativamente a livre circulação de pessoas e de mercadorias.

Em 13 de julho de 2005, a Corte Internacional de Justiça de Haia negou pedido, interposto pela Argentina, em instância de medida cautelar contra o Uruguai, visando interromper a construção das referidas fábricas. Entendeu a Corte Internacional de Justiça de Haia que não estariam devidamente comprovados os supostos danos ambientais. Entretanto, reconheceu que incumbiria ao Uruguai se responsabilizar por qualquer dano ambiental e adotar todas as medidas cabíveis visando à proteção ao meio ambiente.

Sobre o assunto, em recente matéria, assim esclareceu Celso Lafer: ${ }^{3}$ Existe séria controvérsia entre Argentina e Uruguai. Diz respeito à decisão do Uruguai - contestada pela Argentina - de autorizar, no seu território, dois grandes projetos de fábricas de papel e celulose. Alega a Argentina que as fábricas ameaçarão a qualidade das águas do Rio Uruguai, que banham o seu território, com conseqüências para a sua população naquela área.

\footnotetext{
3 Argentina, Uruguai e as 'papeleras' Celso Lafer. O Estado de S.Paulo, São Paulo, 20 ago. 2006. Disponível em: <http://www.estado.com.br/editorias/2006/08/20/opi-1.93.29.20060820.1.1.xml>. Acesso em: 09 set. 2006
} 
No plano geral, a controvérsia está ligada ao tema do desenvolvimento sustentável. Diz respeito à eqüitativa e equilibrada relação que deve prevalecer entre a dimensão ambiental e a econômica de projetos industriais situados num rio transfronteiriço.

Na especificidade do Mercosul a disputa tem grande relevância pelas tensões políticas que vem provocando. Para o Uruguai, trata-se de uma causa nacional, pois esses investimentos são os maiores da História do país, criarão milhares de empregos, representam uma oportunidade de utilização de extensas áreas reflorestadas e adicionarão cerca de $2 \%$ ao produto nacional bruto. Entende o Uruguai que as análises de impacto ambiental dos projetos, impostas por suas autoridades e transmitidas à Argentina, foram rigorosas e que as condições de funcionamento exigidas estão em consonância com os mais altos padrões estipulados no âmbito da União Européia.

A Argentina considera as informações recebidas insuficientes, teme danos irreparáveis à sua economia e ao meio ambiente da região e é sensível aos movimentos populares dos moradores do lado argentino do Rio Uruguai que vislumbram sérios riscos à saúde da população, à piscicultura, à agricultura e ao turismo. Daí o bloqueio-protesto - já suspenso - que esses moradores efetuaram sobre pontes, que impediu a livre circulação de mercadorias no Mercosul, inclusive as provenientes ou destinadas ao Brasil.

A disputa entre a Argentina e o Uruguai - exceção feita ao bloqueio das pontes - não foi encaminhada ao sistema de solução de controvérsias do Mercosul. Nem houve, por parte do Brasil, disposição para mediar a disputa, tal como solicitado pelo Uruguai na esfera do Mercosul. Ela está no âmbito da Corte Internacional de Justiça de Haia, com base num tratado de 1975 - o Estatuto do Rio Uruguai - celebrado e em vigor entre os dois países, que, como outros, coexiste de maneira juridicamente autônoma com o ordenamento do Mercosul.

$(\ldots \ldots \ldots . .$.

No campo mais circunscrito da dimensão jurídica da controvérsia, cabe analisar a sentença da Corte de Haia de 13 de julho, que tratou do pedido argentino de medidas provisórias, equivalentes, no nosso sistema, a uma cautelar. A Argentina pleiteou a suspensão da construção das fábricas e requereu que o Uruguai cooperasse com ela na preservação do meio ambiente do Rio Uruguai, não tomando medidas unilaterais que não estivessem em consonância com o disposto no tratado de 1975. A Corte decidiu que não havia elementos que justificassem uma cautelar, pois a decisão do Uruguai de autorizar a construção das fábricas não constituía uma ameaça iminente de dano irreparável para o meio ambiente do Rio Uruguai e para os interesses socioeconômicos de habitantes ribeirinhos do lado argentino do rio. Ressalvou, no entanto, que o Uruguai assumia os riscos inerentes a qualquer decisão que a Corte venha a tomar quando decidir sobre os méritos da questão e que a construção das fábricas não pode ser entendida como um fato consumado.

$(\ldots \ldots \ldots .$.

No plano jurídico, entendo que a decisão da Corte conteve, no caso, uma aplicação excessiva do princípio de precaução. Também não aceitou o equivalente a um direito de veto da Argentina às papeleras do Uruguai. Neste sentido cabe um contraste com outras normas do Direito Ambiental. Fábricas

A \& C R. de Dir. Administrativo e Constitucional, Belo Horizonte, ano 7, n. 27, p. 121-135, jan./mar. 2007 
de papel e celulose que atendem aos requisitos de controles ambientais rigorosos não comportam uma analogia com movimentos transfronteiriços de resíduos perigosos e seu depósito. Estes são regulados pela Convenção da Basiléia, que se baseia no princípio do consentimento prévio e explícito e reconhece o direito soberano de qualquer Estado de proibir a sua entrada e depósito. Não é o caso das papeleras.

Após a constituição do Tribunal, a Argentina solicitou a suspensão da tramitação do procedimento de solução de controvérsias, por entender que as suas objeções, que resultaram no Recurso apresentado ao TPR, poderiam influenciar na decisão dos árbitros e, ainda, que a mesma era excepcional, ante a existência do Recurso, que não foi conhecido pelo TPR.

Referida preliminar foi afastada pelo Tribunal.

Quanto à participação de terceiros Estados (Brasil e Paraguai), o Tribunal entendeu que, quando intimados, silenciaram-se, não seria oportuno comparecerem às audiências.

O reclamo uruguaio teve como fundamento os prejuízos que os bloqueios realizados na cidade argentina estavam causando para a sua economia, violando-se o Tratado de Assunção, 1991, que visa constituir um Mercado Comum. Entende o Uruguai que no contexto do Mercosul já vigora o sistema de zona de livre comércio, com algumas exceções.

Invoca, ainda, o Protocolo de Montevidéu, referente à livre circulação de serviços, que está em vigor perante ambos os Estados, bem como o Acordo sobre Transporte Internacional Terrestre (AITT), vigente entre os Estados do Cone Sul, além das normas da OMC, como a Cláusula da Nação mais Favorecida, Liberdade de Trânsito e Acesso aos Mercados.

Aduz, ainda, que a questão relativa à livre circulação de pessoas, no contexto da integração, é matéria relativa aos direitos humanos, tutelados em inúmeros tratados sobre a matéria, devidamente ratificados por ambos os países.

Imputa à Argentina a culpa em relação aos referidos protestos, vez que teria a obrigação de combater os referidos protestos.

Aqui verifica-se a maturidade dos Diplomatas, vez que passam a entender a integração como a existência de valores que vão muito além dos aspectos econômicos e comerciais, mas de que a mesma deve adotar políticas voltadas à proteção dos interesses dos cidadãos do Mercosul.

Não obstante, deva-se reconhecer que as decisões adotadas pelos Tribunais do Mercosul raramente levaram em conta os referidos valores, 
o que demonstra a necessidade da existência de uma regulamentação no âmbito regional sobre a matéria relativa aos direitos humanos. O mesmo raciocínio deve ser aplicado com relação à proteção ao meio ambiente e aos direitos sociais, vez que o Mercosul, que pretende se constituir em um Mercado Comum, obrigatoriamente, deverá regulamentar referidas questões, inserindo o cidadão, diretamente, no contexto da integração.

De outro lado, a Argentina contesta o pedido uruguaio, aduzindo que o pedido carece de fundamento, vez que, à época da formalização do pedido, os protestos já haviam cessado. Referida questão foi rechaçada pelo Tribunal, por entender que existe um perigo de dano futuro caso novos protestos venham a ocorrer, sendo necessário o posicionamento do Tribunal, a fim de que defina parâmetros mínimos de conduta, a serem seguidos pelas Partes, na hipótese de surgirem novos incidentes.

Formula, ademais, objeções quanto à instituição do Tribunal na cidade de Montevidéu, por entender que, como o Uruguai é parte no litígio, a decisão poderia ser tendenciosa.

Nesse aspecto, qualquer suspeita quanto ao teor da decisão poderia ser eliminado se as partes optassem em acionar, diretamente, o TPR, que têm sede em Assunção. Há que se reconhecer que a existência de um Tribunal de natureza permanente elimina qualquer dúvida quanto a sua imparcialidade.

Referida preliminar foi afastada pelo Tribunal, vez que o próprio Regulamento do Protocolo de Olivos faculta ao Tribunal $A d \mathrm{Hoc}$ fixar a sua sede em qualquer um dos Estados-Partes do Mercosul.

Entende a Argentina que os manifestos foram realizados por particulares, sem qualquer participação do Estado e que, por sua vez, não poderia interferir diretamente, de forma a coibir referidas manifestações, vez que a competência seria da Província. Ademais, não houve a comprovação de quaisquer prejuízos ao Uruguai.

Relativamente aos direitos humanos, a Argentina utilizou interessante argumento, contrapondo-os aos direitos de expressão e de livre manifestação, que estão assegurados, constitucionalmente, tendo grau de hierarquia constitucional, de acordo com o disposto no artigo 75.22 da Constituição daquele país, ao passo que as normas de integração têm grau de hierarquia legal. ${ }^{4}$

Aqui, deve-se fazer destaque ao fato de que a Argentina autoriza, em sua Constituição, a adoção do instituto da supranacionalidade e, 
não obstante o Mercosul careça da referida característica, vez que o bloco é intergovernamental, caso adotássemos o instituto, certamente as normas decorrentes do direito da integração teriam grã de hierarquia constitucional.

Refuta na totalidade as alegações do Uruguai, entendendo que no Mercosul na vigora o princípio da livre circulação de mercadorias e que as demais normativas não teriam aplicabilidade.

Voltando às questões decorrentes dos direitos humanos, entendem que a violação dos referidos direitos poderiam caracterizar uma justificativa para impor barreiras não tarifárias ou uma restrição ao direito da integração, e se interviesse no combate às referidas manifestações, além de violar os direitos humanos, estar-se-ia imiscuindo em competência estrita das Províncias, violando-se os princípios democráticos de um Estado de Direito.

Cumpre asseverar que os valores relativos a Democracia e Direitos Humanos devem ser entendidos como elementos essenciais para a integração e não como medidas para justificar limitações ao livre-comércio. Somente em situações justificadas e excepcionais é que referidas restrições poderão ser adotadas.

Verifica-se, nesse aspecto, que os nossos Estados-Partes carecem de valores próprios da integração, vez que estão arraigados aos valores soberanófilo e estatólatra do começo da década de 50.

Caso o Mercosul deseje avançar, com a finalidade de obter maiores êxitos no processo integracionsta, os Estados-Partes deverão estar comprometidos em adotarem políticas conjuntas, visando à proteção da Democracia e dos Direitos Humanos.

Produzidas as provas e colhidos os depoimentos testemunhais, o Tribunal passou a decidir.

Quanto à matéria de fundo, uma vez superadas e refutadas as alegações preliminares, o Tribunal entende que o Mercosul é um processo em desenvolvimento, que objetiva se consolidar em um Mercado Comum e, como tal, devem ser adotadas medidas conjuntas visando eliminar as restrições comerciais, fazendo alusão ao disposto no artigo $1^{\circ}$ do Tratado de Assunção de 1991, que dispõe sobre a futura formação do Mercado

\footnotetext{
4 Não obstante deva-se reconhecer que a Argentina autoriza a participação do Estado em instituições de caráter supranacional, em condições de reciprocidade, desde que respeitados a democracia e os diretos humanos. (Artigo 75 da Constituição daquele país).
} 
Comum, que implica na eliminação gradual das barreiras tarifárias e nãotarifárias, para que haja a livre circulação de bens, pessoas e dos fatores de produção.

Quanto aos protestos, realizados pelos argentinos, entendeu o Tribunal que, não obstante os mesmos fossem legítimos, o movimento extrapolou, causando prejuízos para os cidadãos uruguaios, relativamente aos serviços de turismo, transporte e outros.

Quanto à responsabilização da Argentina, o Tribunal perquiriu se o Estado teve culpa para a ocorrência dos referidos fatos, isto é, se foi omisso, no sentido de manter o poder de polícia, para garantir a livre circulação de serviços, concluindo que caberia à parte reclamada (Argentina) velar pela livre circulação de serviços, sendo, ainda, responsável pelas omissões dos governos das Províncias.

Quanto à aplicação das normas de Direitos Humanos, o Tribunal entendeu que as referidas questões são de direito interno e não possuem qualquer relação com o direito da integração e qualquer restrição ao comércio internacional, invocando o direito interno implicaria na violação ao Tratado de Viena, artigo 27, no qual a parte não pode invocar uma norma de direito interno, como justificativa para descumprir o tratado.

Aqui a Argentina, com a celebração do Tratado de Assunção, 1991, comprometeu-se na formação de um Mercado Comum.

Fundamentou a sua decisão, aduzindo que as normas de direito constitucional, relativas aos direitos humanos, não teriam qualquer aplicabilidade no contexto do Mercosul, não obstante, conforme nosso posicionamento acima, referidas normas devem ser examinadas como elementos integrativos do Mercosul, visando proteger e beneficiar os interesses dos cidadãos do bloco.

Contemporaneamente, nítida é a relação entre o Direito Constitucional e o Direito da Integração do Mercosul, eis que ambos convivem de forma harmônica em uma relação quase de simbiose, em que no âmbito interno as normativas emanadas pelas instituições do bloco acarretam direitos e deveres aos particulares, quando internalizadas; e, no plano na integração, com a observância por parte dos Estados de valores voltados à democracia e aos direitos humanos, cada vez mais o Mercosul deve se preocupar com as referidas políticas.

Quanto às manifestações, o Tribunal entendeu que as mesmas, com o passar do tempo, foi perdendo a legitimidade, sendo que as controvérsias 
devem ser solucionadas de forma pacífica.

Quanto à relevância dos prejuízos, o Tribunal entendeu que a sua função precípua é de corrigir eventuais medidas que estejam distorcendo com o comércio regional, de forma a determinar que o Estado reclamado venha a eliminá-las e, somente em um momento posterior, caso as medidas não sejam adotadas, torna-se possível a adoção de medidas compensatórias ou de efeito equivalente, a exemplo do sistema adotado na OMC e no Nafta.

O Tribunal justifica o referido posicionamento, entendendo que a adoção das referidas medidas podem causar dificuldades no comércio entre os países.

Assim, a decisão do Tribunal foi no sentido de determinar que o Estado argentino adote medidas, visando prevenir eventuais futuros protestos na região, de forma a oferecer garantias adequadas para que futuros protestos não venham a ocorrer.

Sem dúvida, trata-se de um precedente importantíssimo, no contexto do Mercosul, notadamente porque a controvérsia envolveu uma economia menos favorecida, que é o Uruguai e que está recebendo investimentos na ordem de U $\$ 1,8$ bilhões de dólares.

A controvérsia em questão, mais do que questões relativas ao livre comércio e ao meio ambiente, tratou com questões sensíveis a qualquer processo de integração, como é o caso do direito à exploração econômica e sustentável do meio-ambiente, proteção aos direitos humanos e à democracia.

Na seara do Mercosul, trata-se de valores que, agora, começam a ser debatidos e que, cada vez mais, estarão presentes nas agendas de nossos negociadores, tornando-se necessária, mais do que nunca, a participação direta, do cidadão, no contexto da integração, a fim de que venha a definir os objetivos que melhor lhes interessam.

\section{Considerações finais}

No contexto do Mercosul, as controvérsias entre os Estados-Partes passam a ter uma outra dimensão daquelas até então existentes, referente aos temas econômicos e comerciais.

As dimensões passam a abordar temas como o desenvolvimento sustentável dos Estados-Partes, proteção ao meio ambiente, democracia e direitos humanos, condicionantes essenciais para o sucesso de qualquer processo de integração. 
No atual estágio de crise do Mercosul, os Estados-Partes devem pautar as suas políticas na busca de um melhor desenvolvimento não só econômico, mas principalmente social dos Estados, como forma de valorizar a democracia e os direitos humanos, a fim de que o cidadão possa ser inserido, diretamente, no contexto das políticas a serem adotadas pelos parceiros.

Certo é que no Mercosul, que visa à formação de um mercado comum, as controvérsias têm como principal fundamento as questões referentes à imposição de barreiras tarifárias e não tarifárias que limitam o livre-comércio no âmbito regional.

Com o aprofundamento do processo de integração e a politização da sociedade, outros temas passam a ser objeto de controvérsias, os quais, não obstante tenham cunho comercial, no fundo, dizem respeito a valores muito mais importantes ao cidadão, como os examinados nos dois laudos arbitrais: a proteção da democracia e dos direitos humanos.

Entretanto, pretender invocar a proteção dos referidos direitos, como forma de justificar eventuais restrições ao comércio regional, é um equívoco. O caminho há que ser inverso, na medida em que referidas questões, cada vez mais, estão inseridas no contexto do Mercosul, assim, a proteção aos direitos humanos, ao meio-ambiente e à democracia devem ser políticas que tenham por finalidade desenvolver o processo integracionista que, conforme reconhecido nos laudos arbitrais, o nosso bloco econômico é um processo em evolução e que deve levar em conta referidos conceitos, fundamentais para qualquer sociedade.

E por se caracterizar como um processo em evolução, cada vez mais, o cidadão do Mercosul deverá ser inserido nas políticas do bloco econômico, de forma que as decisões, adotadas pelas instituições do Mercosul, possam ter a devida legitimidade.

Por fim, importante destacar que, se no âmbito do comércio muitos duvidam do sucesso do Mercosul, ele não pode ser desprezado como condição essencial e estratégica, para que os nossos Estados busquem um modelo próprio de desenvolvimento, o que somente será possível se o bloco econômico regulamentar questões essenciais para a política da integração, como a proteção aos direitos humanos, democracia e meio ambiente, de forma que referidas políticas possam ser aplicadas no contexto da integração e não como justificativas para o Estado adotar barreiras não-tarifárias.

A \& C R. de Dir. Administrativo e Constitucional, Belo Horizonte, ano 7, n. 27, p. 121-135, jan./mar. 2007 
Abstract: Enviromental protection and sustainable development, are growing in the international context. This article approach two famous cases of the Olivo's Permament Tribunal of Revision, that involves relevant subjects: democracy and human rights protection.

Keywords: Mercosur. Olivos’s Protocol. Human Rights. Enviromental Protection. Non tarifary- barriers.

Informação bibliográfica deste texto, conforme a NBR 6023:2002 da Associação Brasileira de Normas Técnicas (ABNT):

GOMES, Eduardo Biacchi. Democracia, direitos humanos e proteção ao meio ambiente no contexto da integração regional. A\&C Revista de Direito Administrativo e Constitucional, Belo Horizonte, ano 7, n. 27, p. 121-135, jan./mar. 2007. 